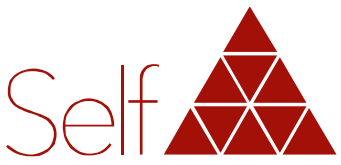

Revista do Instituto Junguiano de Săo Paulo

\title{
O "Livro vermelho": a escolha de Jung em produzir sua obra alquímica como livro
}

\section{Mônika OLIVEIRA}

Rio de Janeiro, RJ, Brasil.

\section{Resumo}

Uma das vias para a compreensão do "Livro vermelho" é relacioná-lo ao processo da opus (obra) alquímica ou opus magna, o trabalho dos alquimistas para a obtenção da pedra filosofal. Carl Gustav Jung usa esse processo na formação do "Livro vermelho", fato que ele mesmo foi compreender somente a posteriori. Lembrando que seu primeiro contato com textos alquímicos se deu em 1910 e que as atividades em relação ao "Livro vermelho" ganharam força entre 1913 e 1930, podemos entender que esta publicação e a alquimia têm uma relação causal. A percepção de que a psique segue os mesmos passos dos símbolos alquímicos no processo da individuação influenciou a psicologia analítica de maneira determinante. Nas etapas de elaboração da obra alquímica é revelada uma sequência de símbolos alquímicos que compõem o processo. $\bigcirc$ presente trabalho

Conflito de interesses:

A autora declara não haver nenhum interesse profissional ou pessoal que possa gerar conflito de interesses em relação a este manuscrito. pretende demonstrar que 0 "Livro vermelho" segue uma conduta alquímica e que é nesta obra que Jung encontra o seu caminho pessoal rumo à individuação.

\section{Descritores}

símbolos, linguagem, individuação, imagem. 


\title{
The "Red book": Jung's choice to produce his alchemical work as a book
}

\begin{abstract}
One way of understanding the "Red book" is to relate it to the process of the alchemical opus or opus magna, the work of alchemists to obtain the philosopher's stone. Carl Gustav Jung uses this process in the development of the "Red book", a fact that he had only understood a posteriori. Recalling that his first contact with alchemical texts occurred in 1910, and that the activities related to the "Red book" gained strength between 1913 and 1930, we can understand that this publication and alchemy have a causal relationship. The perception that the psyche follows the same steps of the alchemical symbols, during the process of individuation, has influenced analytical psychology in a very determinant manner. In the stages of development of the alchemical work, a sequence of symbols that compose the process are revealed. The present paper intends to demonstrate that the "Red book" follows alchemical conduct and that it is in this book that Jung finds his personal path towards individuation.
\end{abstract}

\section{Descriptors}

symbol, language, individuation, imagery.

\section{El "Libro rojo": la decisión de Jung de producir su obra alquímica como libro}

\section{Resumen}

Una de las vías para la comprensión del "Libro rojo" es relacionarlo al proceso de la Gran obra u Opus magnum, trabajo de los alquimistas para la obtención de la piedra filosofal. Carl Gustav Jung utiliza este proceso en la creación del "Libro rojo", hecho que él mismo sólo entendió a posteriori. Recordando que su primer contacto con textos alquímicos se dio en 1910, y que las actividades relacionadas con el "Libro rojo" ganaron fuerza entre 1913 y 1930, podemos entender que esta publicación y la alquimia tienen una relación causal. La percepción de que la psique sigue los mismos pasos de los símbolos alquímicos en el proceso de individuación influenció la psicología analítica de manera determinante. En las etapas de elaboración de la obra alquímica se revela una secuencia de símbolos alquímicos que componen el proceso. El presente trabajo propone demostrar que el "Libro rojo" sigue una conducta alquímica y que es en esta obra que Jung encuentra su camino personal hacia la individuación.

\section{Descriptores}

símbolo, lenguaje, individuación, imágenes. 


\section{Introdução}

homem civilizado, que criou seu novo modelo de natureza, esbarra sempre em um não pertencimento de si mesmo e na não identificação da própria vida; ele cria e reconhece o livro apenas como objeto e fonte de conhecimento. Mas a alquimia é um acelerar os fazeres da natureza em laboratório que precisa não apenas das misturas de matérias e cadinhos, como também de uma linguagem própria. $\bigcirc$ livro alquímico torna-se assim um símbolo linguístico.

Para os alquimistas, o livro era a realização da obra alquímica ou opus. Eles tinham por prática a elaboração de textos e de livros. O líber (livro) era um objeto das técnicas da arte alquímica, que possuía linguagem própria e hermética. Muitas vezes os alquimistas uniam textos com iluminuras na formação desses códices.

É possivel fazer uma analogia entre a elaboração do códice e o elemento mítico, a pedra filosofal ou lápis philosophorum, ou ainda, o ouro filosofal, o objeto de desejo dos alquimistas. Acreditava-se que com a pedra seria possível transmutar qualquer metal inferior em ouro e também obter o elixir da longa vida, a conquista da eternidade. Sem uma aparência física definida, a pedra filosofal relacionava-se com a forma circular e com a cor vermelha. A finalidade de se tentar alcançar a pedra era a de adquirir sabedoria e iluminação.

\section{A importância do códice para a opus alquímica}

Propomos olhar o livro alquímico como representante simbólico da pedra filosofal. Fazer um livro colabora para a organização psíquica necessária ao processo de individuação. No "Livro vermelho", Jung dedicou-se como a um "vaso", no qual pode trabalhar seu próprio psiquismo, o que o levou em direção a sua individuação.

A pedra é um dos símbolos do self, o centro organizador de onde emana a ação reguladora do nosso sistema psíquico. Como símbolo do self, a pedra é vista como um vaso que tem em seu potencial transformador a força criativa, por onde a obra alquímica deve acontecer. Em seu livro "Estudos alquímicos", Jung afirma que a pedra contém e é o próprio si-mesmo (Jung, 2003, p. 88-89, OC XIII: 115). Outra comparação importante do si-mesmo e a pedra relaciona-se ao Santo Graal, um cálice de onde se pode beber da fonte da sabedoria.

No "Líber quartorum", livro alquímico de origem árabe que aparece entre os séculos III e IV - que tratava também da geometria, fisiologia e astrologia -, temos que a transformação está na cabeça, sendo um processo psíquico. A "forma redonda" pode ser associada a mandalas ou a círculos mágicos (Jung, 2003, p. 89-90, OC XIII: 117). 
Jung afirma que nos símbolos alquímicos encontramos a forma do crânio humano como vaso (Figuras 1 e 2). Isso indica o uso do pensamento e do intelecto como parte significativa no processo da opus. Em Jung, lemos: "Assim sendo, o Líber quartorum recomenda que se use o 'occiput' (isto é, a parte posterior do crânio humano) como vaso de transformação [...], por nele estarem contidos o pensamento e o intelecto." (Jung, 1994, p. 279, OC XII: 376)

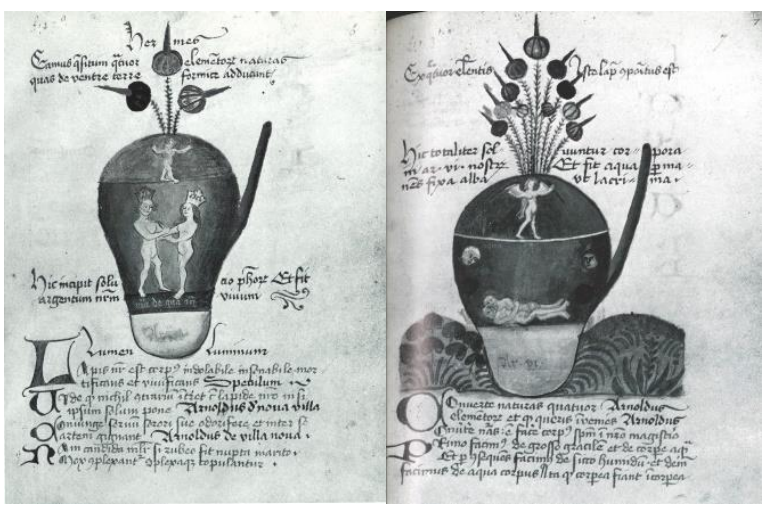

Figuras 1 e 2. Ilustrações alquímicas apresentando o crânio como um vaso. Reproduzida de The Secret Art Alchemy, de Johannes V. Andreae, $15^{\text {th }}$ Century, British Museum, London, Sloane 2560 (f. 6-7). Copirraite 2017 pelo British Museum.

Segundo Neumann (2006, p. 169): "Os vasos de morte e transformação do mundo inferior também têm formato de crânios" e se encontram no simbolismo da fertilidade, do grande feminino. Como a alquimia está ligada à transformação e à sabedoria - ou sophia que, por sua vez, é representada pelo feminino -, assim também nas formas do vaso e do cálice vemos o simbolismo da Grande Mãe que os povos primitivos sempre cultuaram.

Podemos encontrar imagens do crânio em obras de artistas de várias épocas. Didi-Huberman (2009), em seu livro "Ser crânio", comenta trabalhos de artistas como Albrecht Dürer (Figura 3) e Giuseppe Penone. Ele mostra a relação do crânio com um átrio, o espaço aberto ou fechado que fica diante do portal de uma igreja - no pensamento alquímico, o lugar do pensamento. $\bigcirc$ autor comenta que o crânio é também chamado de "têmpora inquieta" e que mobiliza questões ontológicas, como a busca de Deus. A caveira como uma calota "é o cálice humano que recolhe o sangue divino, o cálice de pecado que recolhe o fluxo de sua futura redenção" ( $p$. 40). Ele segue: "Ela é também, antes de tudo, o lugar-nomeado da morte de Cristo, um crânio topônimo, um lugar de fundação para uma religião inteira" (Didi-Huberman, 2009, p. 40). 


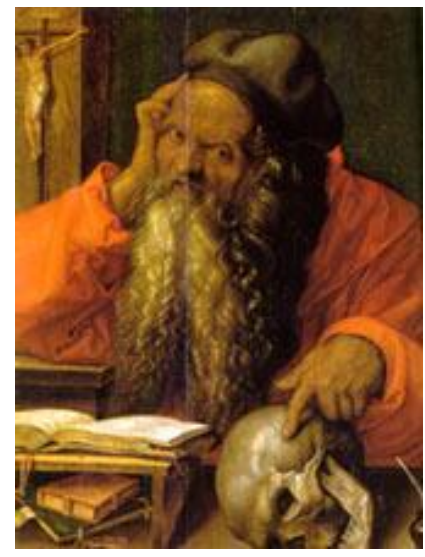

Figura 3. São Jerônimo, Albrecht Dürer, 1521. Reproduzida de https://pt.wikipedia.org/wiki/Ficheiro:Lisboa-Museu_Nacional_de_Arte_AntigaS\%C3\%A3o_Jer\%C3\%B3nimo-20140917.jpg. Copirraite 2016 por D. Villafruela [(CC BY-SA 3.0)].

Esses símbolos surgem independentemente da época em que foram expressos. Existem inúmeras representações nas quais o poder divino no homem é representado pela cabeça, que, por sua vez, também é reconhecida como sede do pensamento, do intelecto e do psiquismo. Imagens de santos possuem auréolas ou cabeças envoltas por uma luz; nas produções artísticas da Idade Média, a cabeça é ilustrada como luz divina. $\bigcirc$ poder divino do homem habita a cabeça, como mostram as Figuras 4 e 5 (exemplos de pinturas medievais com cabeças destacadas com halos dourados, indicando seres espirituais, sagrados).

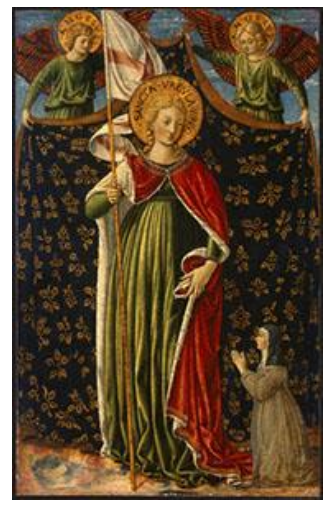

Figura 4. Saint Ursula with Two Angels and Donor, Benozzo Gozzoli, 1455-1456. Reproduzida de https://commons.wikimedia.org/wiki/File:UrsulaGozzoli.jpg. Copirraite 2017 pelo Smithsonian American Art Museum in Washington, D.C [(CC BY-SA 3.0)]. 


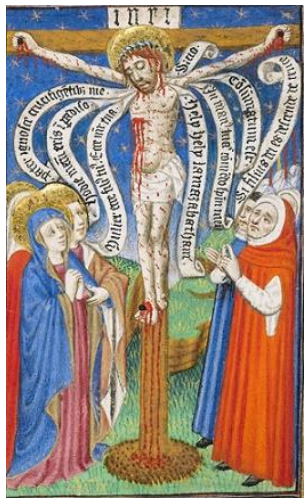

Figura 5. The Seven Last Words of Christ (detail), from a book of hours, Master of Sir John Fastolf, about 1430-40. Reproduzida de http://www.getty.edu/art/exhibitions/gospel_illuminations/299701_enlarge.html. Copirraite [s.d.] por J. Paul Getty Trust

Como o códice é uma sequência de pensamentos, organizada e numerada no tempo, o tempo é, junto com o pensamento, parte de uma sequência que compõe as partes do livro. Dessa maneira, podemos compreender que o livro reúne não apenas uma sequência de ideias como também o tempo em si, que é uma indicação alquímica, como podemos ver em Jung (1994) que extrai do Liber Quartorum uma importante informação para a "grande transformação" se dar:

As coisas são transformadas através do tempo e de definições mais precisas em intelecto, na medida em que as partes são assimiladas umas às outras na composição e na forma. Mas por estar mais perto da "anima rationalis" o cérebro assimilou-se à mistura e, como dissemos a anima racionalis é simples (p. 279, OC XII:376)

Para Jung, a obra dos alquimistas estava ligada à alma humana e a suas funções. Ele entende que o segredo da arte alquímica estava oculto no espírito humano e, portanto, em termos modernos, no inconsciente. Diz Jung (1994): "Eles insistem, sem exceção, no estudo meticuloso dos livros e na meditação dos mesmos." (p. 269, OC XII: 362).

Em muitos textos alquímicos existia a recomendação de se fazer os registros do trabalho da opus em códices. Aquele que desejava realizar a obra deveria passar pelo estudo da filosofia universal e esta the revelaria aquilo que permanecia oculto e desconhecido aos demais. 
Segundo Jung (1994),

Dionysios Zacharius conta que foi aconselhado por um "religiosus doctor excellentissimus" a abster-se de gastos inúteis em "sophisticationibus diabolicis" (sofística diabólica), dedicando-se de preferência ao estudo dos livros dos velhos filósofos, a fim de travar conhecimento com a "vera matéria" (verdadeira matéria). (p. 271, OC XII: 376)

O trabalho dos alquimistas relacionava-se não apenas à matéria, mas, simultaneamente, ao intelecto; o livro é o vaso para o trabalho do intelecto. $\bigcirc$ ato de extrair a verdade, tão obstinadamente perseguido pelos alquimistas, se encontra na razão (mens).

O ser humano é tanto o alvo como o processo para se chegar à pedra. $\bigcirc$ códice participa da intuição e do intelecto, tornando-se ponte entre matéria e espírito. Nele, a impressão, os desenhos e a escrita têm função singular, transcendente, um terceiro elemento entre o ego e o inconsciente. Os alquimistas se dedicavam incansavelmente a encontrar a pedra.

Como um processo intelectual alcança um conteúdo espiritual? Como esse processo se encontra dentro da matéria? Para Jung, existe uma série de correspondências entre o opus alquímico e os processos filosóficos, psicológicos e espirituais. A química da matéria coincide com fenômenos espirituais ou, melhor dizendo, psíquicos. Porém, para essa transformação da matéria acontecer, o operador deve estar presente na obra. Jung afirma que há uma conexão íntima entre o ser humano e o segredo da matéria e que o intelecto parece ser esse "atravessador" entre um estado e outro, entre a matéria e o espírito.

Os alquimistas faziam suas experiências na matéria e, em seguida, escreviam seus códices. Temos o livro simultaneamente como prima matéria e como obra, como causa e efeito acontecendo ao mesmo tempo. O livro reúne ambos.

Rudolf Arnheim (2004) afirma que é na duplicidade da mente, que usa a intuição e o intelecto, que se "sustentam todas as operações da aprendizagem produtiva em todos os campos do conhecimento" (p. 13). Arnheim (2004) diz que, ao empregar essas duas funções, estamos utilizando tanto o hemisfério direito como o esquerdo do cérebro: é no uso simultâneo de ambos que pode acontecer o fenômeno de função transcendente, agente do equilíbrio psíquico, união dos conteúdos conscientes e inconscientes do ser:

A intuição e o intelecto são os dois processos cognitivos. Por cognição entendo, aqui, a aquisição de conhecimento no sentido mais amplo do termo. Assim entendida, ela vai desde o registro mais elementar de sensações até os registros mais sofisticados da experiência humana. (Arnheim, 2004, p. 15) 
No "Livro vermelho" Jung utiliza o termo vera imaginatio, ou seja, uma forma de imaginação ativa na qual os conteúdos inconscientes se manifestam à consciência por uma espontaneidade imaginativa. Tais registros se encontram no arcabouço psíquico pertencente ao inconsciente coletivo.

Segundo Ernest Cassirer (2005), Kant entende o movimento intuitivo como um veículo que nos leva à natureza e aos limites do intelecto humano. Não podemos pensar sem imagens e não podemos intuir sem conceitos. Cassirer (2005) afirma que o intelecto humano precisa de símbolos: "O conhecimento humano é por sua própria natureza um conhecimento simbólico. E é este traço que caracteriza tanto a sua força como as suas limitações." (p. 96). Cassirer (2005) nos diz ainda que: "um símbolo não tem existência real no mundo físico; tem um sentido" (p. 97).

É na dialética entre a matéria e o espírito que se baseia a opus alquímica e também o desenvolvimento da personalidade, como acreditou Jung. $\bigcirc$ ser é tanto corpo e matéria, como pensamento e espírito; e ambos os lados deste ser podem ser reconhecidos. $\bigcirc$ mundo espiritual e intuitivo se revela por meio de imagens. Assim, a imagem parece ser então o elo entre os universos consciente e inconsciente, em relação direta com a função transcendente. $\bigcirc$ "Livro vermelho" é formado em boa parte por diálogos entre a consciência (o ego) e a psique objetiva (o inconsciente), o percurso intuitivo que o guiou.

Segundo Arnheim (2004), Platão considera "a intuição como o mais alto nível da sabedoria humana visto que proporciona uma visão direta das essências transcendentais, às quais todos os fatos da nossa experiência devem a sua presença" (p.15). Dessa forma, sob a óptica da filosofia metafísica, os alquimistas podem ser considerados visionários.

\section{Iluminuras}

O termo "iluminura" não representa meramente uma ilustração, pois é de natureza simbólica, possuindo sentido de metaimagem: a iluminura existe para iluminar um texto. A iluminura da Arte Medieval, ao representar um contexto que vai além da imagem em si, esboça um espírito de época voltado à conexão com o sagrado. Parece compreensível a preocupação de Jung em expressar suas imagens internas como iluminuras.

Essas miniaturas se tornaram uma ponte à compreensão dos conteúdos vindos do imaginário, carregadas de forças anímicas, dando origem aos símbolos alquímicos. As iluminuras dos alquimistas conferem certa magia à representação de seu conteúdo. Mas, como todo conteúdo esotérico, a alquimia não trata apenas de transformações materiais. Aqueles que compreenderam a razão da verdadeira alquimia conseguiram realizar a única transformação que vale a pena: a alquimia espiritual. 
Sob esse aspecto, a alquimia se apresenta como um manual voltado à busca espiritual. Jung entendeu que a alquimia estava ligada ao processo psíquico, no qual o indivíduo explora o material do seu inconsciente, na tentativa de transformar a mente consciente, alcançando a luz espiritual e descobrindo a si próprio.

Um símbolo genuíno não é uma designação abstrata, livremente escolhida e ligada a um objeto específico por convenção (tais como signos verbais ou matemáticos), mas a expressão de uma experiência espontânea que aponta para além de si mesma na direção de um significado que transcende o racional. $\bigcirc$ fato de Jung ter se dedicado à expressão visual, unindo o imaginário à ciência, fez com que sua obra apresentasse uma linguagem amplificadora da consciência, na qual podemos perceber o indizível e significá-lo.

Cassirer (2005) refere-se ao símbolo como uma chave para entendermos a natureza do homem e reconhece que este

[...] não vive em um mundo de fatos nus e crus, ou segundo suas necessidades e desejos imediatos. Vive antes em meio a emoções imaginárias em esperanças e temores, ilusões e desilusões, em suas fantasias e sonhos. Não estando mais em um universo meramente físico, o homem vive em um universo simbólico. A linguagem, o mito, a arte e a religião são partes desse universo. (p. 49)

Gilbert Durand (2002) também reconhece a natureza não linear do símbolo:

O símbolo, não sendo já de natureza linguística, deixa de se desenvolver numa só dimensão. As motivações que ordenam os símbolos não apenas já não formam longas cadeias de razões, mas nem sequer cadeias. A explicação linear do tipo dedução lógica ou uma narrativa introspectiva já não bastam para o estudo das motivações simbólicas. (p. 32)

Durand (2002) prossegue dizendo que "o caráter pluridimensional, portanto 'espacial' do mundo simbólico, é essencial." (p. 32). É nessa complexidade que Jung se debruça para tecer um caminho para uma melhor compreensão do ser humano.

$\bigcirc$ alquimista desenvolveu uma linguagem pseudoquímica, revestida por símbolos e textos herméticos, guardados como um segredo: não queriam que tais informações caíssem em mãos erradas. Jung (1994) ressalta que: "os alquimistas tinham pouco ou nada a divulgar no tocante à química e ainda menos ainda no tocante à fabricação do ouro" como metal (p. 271, OC XII: 343). Ele percebeu que eles lidavam muito mais com experiências de transformações espirituais internas, do que com os procedimentos no laboratório e seus relatos. 
O livro, para os alquimistas, seria uma elaboração da representação de conteúdos inconscientes projetados na matéria de forma espontânea, involuntária. Na verdade, a obra alquímica trata do confronto com o inconsciente: a opus consiste no encontro entre a mente racional e a mente fantasiosa. Para Jung (2003):

Tratava-se do confronto alquímico com o inconsciente, do "labor Sophiae" de Paracelso. Por um lado, tal confronto é o esforço de compreender o mundus archetypus da alma: por outro, é a luta contra o perigo da fascinação que ameaça o lado racional, o qual procede das alturas e profundidades incomensuráveis do paradoxo da verdade anímica sem mediação. (Jung, 2003, p. 89-90, OC XIII: 210)

livro torna-se um recipiente ideal para abrigar o paradoxo necessário para a obra acontecer, o confronto do homem com sua própria origem. $\bigcirc$ livro aparece também como símbolo do segredo divino, que só é confiado ao iniciado.

\section{Processo de individuação e autoconhecimento de Jung}

Jung procurou uma linguagem própria. $\bigcirc$ percurso do "Livro vermelho" tem uma diferença significativa em relação aos livros compostos pelos alquimistas: Jung foi buscar o conteúdo de seu livro diretamente na sua fonte inconsciente, na mente primitiva, nos seus sonhos e na imaginação ativa. Essa foi a forma de Jung "mexer na matéria". Esse trabalho passou a ser a representação de sua prima matéria, onde ele se colocou como objeto do processo. É dessa maneira que ele transforma os conteúdos em um códice de imagens e textos. Por esse motivo, até podemos enxergar o "Livro vermelho" como um processo alquímico moderno. Jung precisou de um grande esforço para elaborar uma linguagem que lhe fosse própria, porém, sem ter a noção exata de onde essa obra acabaria. Sua obra comporta símbolos pertencentes a toda humanidade. Esses conteúdos pertencem ao inconsciente coletivo. Como Deirdre Bair (2006) comenta:

Quando leu antigas obras alquímicas, Jung encontrou paralelos interessantes entre seus autores e muitos textos criados por religiosos místicos, anacoretas e outros visionários, especialmente dentro da tradição cristã. Para ele a alquimia tratava mais do processo de crescimento interno, que ele chamava de individuação, e, como tal, tornou-se a metáfora dele para o processo de transferência no interior do encontro analítico, à medida que esse processo evoluiu em sua psicologia. (p. 57)

"Liber novus" é o nome alquímico do "Livro vermelho". Os alquimistas manipulavam a matéria e, por meio de técnicas, obtinham revelações que surgiam como imagens formadoras de seus símbolos e códigos. Uma das iluminuras do "Livro vermelho" (Figura 6), correspondente a um vaso-crânio, se mostra como uma calota craniana em formato de mandala, contendo as 
cores correspondentes às etapas alquímicas. No centro, vemos um quatérnio, indicação do self, metade da calota submersa em água, podendo indicar o mergulho no inconsciente, a psique objetiva, e a outra metade, no ar, simbolizando a psique racional. Aí está a base formativa do "Livro vermelho".

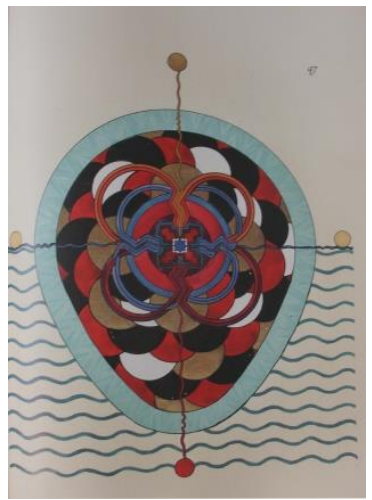

Figura 6. Iluminura de Jung. Reproduzida de Livro Vermelho, de C. G. Jung (2010) (p. 97).

Segundo os alquimistas, em seu processo de transformação, a matéria passaria pelos seguintes estágios: (a) nigredo ou "operação negra", fase na qual a matéria é dissolvida e putrefeita, em uma operação feita com a utilização do fogo ou do calor; em termos psicológicos, relacionamos essa etapa ao próprio material inconsciente; (b) albedo ou "operação branca", estágio em que a substância é purificada, associado à ablução com aquae vitae, à luz da lua, ao feminino e à prata, uma tomada de consciência dos aspectos inconscientes que ainda não foram revelados, mas que são vitais para o autoconhecimento; (c) citrinitas ou "operação amarela", etapa em que se opera a transmutação dos metais, da prata para o ouro, ou da luz da lua (passiva) para luz solar (ativa); neste estágio, a tomada de consciência é sentida com mais força; e (d) rubedo ou "operação vermelha", fase final, quando se produz a pedra filosofal, o culminar da obra, ou o "casamento alquímico"; este estágio simboliza o clímax do processo de individuação.

Em muitos textos alquímicos só existem referências a três etapas: nigredo, albedo e rubedo, considerando que citrinitas e rubedo têm características bem próximas no que diz respeito ao efeito espiritual (Figura 7).

Jung começou esse processo de individuação e autoconhecimento com os "Livros negros" e depois passou para o "Livro vermelho", motivo e objeto da opus de Jung. Para cumprir essa meta foi preciso motivação, além do simples desejo - trata-se de obstinação. 


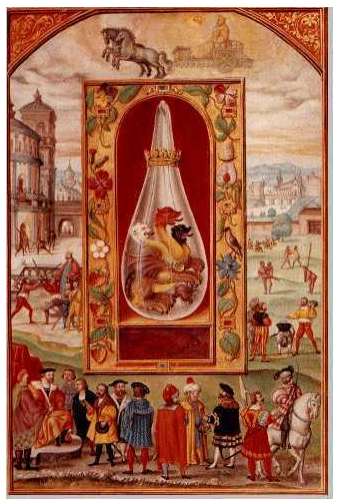

Figura 7. Iluminura alquímica: cabeças de dragão indicando albedo, rubedo e nigredo. Reproduzida de Plate XV- The fourth treatise, fourthly. Splendor Solis, 1582, http://www.chymist.com/Splendor\%20solis.pdf.

Jung estava à procura de sua própria linguagem, oscilando entre sua mente intuitiva e sua mente racional, e escolheu utilizar recursos da pintura da Arte Medieval, como a caligrafia gótica e o alemão medieval. Nessa busca bastante elaborada, ele se encontrou com seu próprio mito pessoal, representado pelo herói mitológico lzdubar, personagem que aparece em várias cenas do livro, trajando uma roupa listrada de azul e branco. Assim como os heróis da Antiguidade, Jung tinha imenso respeito e temor pelas figuras primitivas, mitológicas. Dessa forma, ele conseguiu atingir mais do que uma linguagem própria: alcançou uma cosmologia pessoal, como Shamdasani (2010) indica em sua introdução ao "Livro vermelho".

Para Walter Boechat (2014), Izdubar pode ter sido uma figura mítica de inspiração na travessia imagética da obra:

C confronto de Jung com lzdubar representa na verdade o confronto do pensamento racional consciente (Jung) com o pensamento mitológico do inconsciente (Izdubar). As diversas ilustrações desse encontro mostram um Jung como uma figura diminuta respeitosa, frente a um lzdubar gigantesco. Izdubar representa toda a tradição que a humanidade traz em sua história memorável, todas as suas aquisições e aprendizados depositados como memória ancestral no inconsciente coletivo. (p. 67)

Considera-se que Izdubar seja o mesmo personagem que Gilgamesh, um poderoso rei da Suméria que viveu por volta de 3.500 a.C. (Figura 8). 


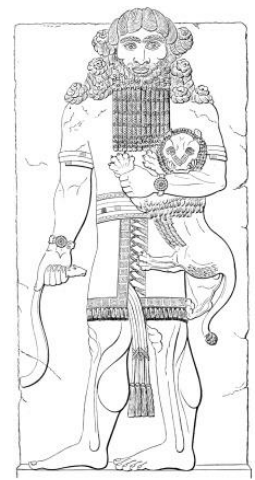

Figura 8. "Izdubah strangling a lion. From Khorsabad sculpture", 1876, George Smith (assyryologist), The Chaldean Account of Genesis. Reproduzida de Wikimedia: https://commons.wikimedia.org/wiki/File:Izdubar.png

Associações com deuses imortais e com o sol (Figura 9) fazem com que nosso processo existencial ganhe sentido ontológico e, por isso, coletivo. Jung (1986) expressa essa visão quando diz que:

O homem de fato é mortal, mas há exceções, existem homens imortais, ou alguma coisa em nós que é imortal. Assim os deuses ou um Chidr ou um Comte de Saint-Germain são aquela parte nossa imortal que paira algures, inatingível. A comparação com o Sol sempre de novo nos mostra que a dinâmica dos deuses é energia psíquica; ela é a parte imortal, representando aquele elo através do qual o homem se sente integrado para sempre na continuidade da vida. (p. 186-187, OC V: 296)
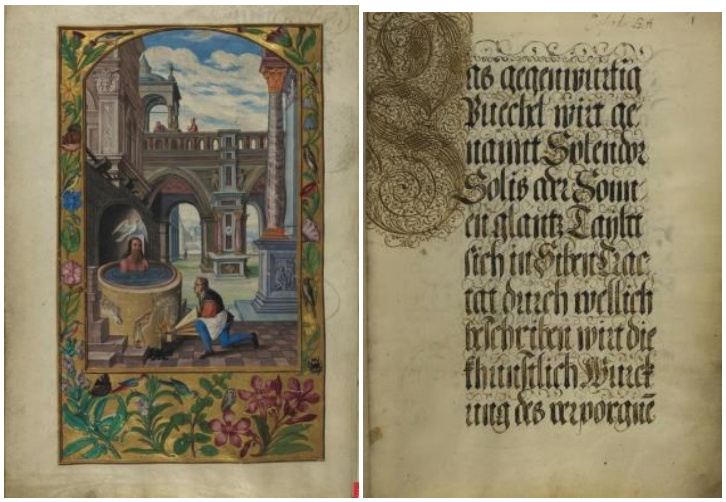

Figura 9. Iluminura e texto do "Splendor Solis". Reproduzida de Plate XI - The seventh parable. Splendor Solis, 1582, http://www.chymist.com/Splendor\%20solis.pdf 
Cassirer (2005) afirma que, para a mente primitiva, mito e linguagem são como "irmãos gêmeos", pois se baseiam na natureza social, antes do que na física, na medida em que transferem essa experiência social para a totalidade da natureza. Jung também estava em busca dessa natureza primitiva dentro de si: o "Livro vermelho" é um resgate de várias partes de sua personalidade, podemos dizer que é o seu Graal.

\section{Considerações finais}

$\bigcirc$ encontro de Jung com os primeiros textos da alquimia teve início em 1910, sob a influência dos trabalhos de Théodore Flournoy e Herbert Silberer. Flournoy apresentou uma interpretação psicológica da alquimia em suas preleções na Universidade de Genebra, em 1912. Em 1914, Silberer publicou uma extensa obra sobre o tema. (Shamdasani, 2010)

Jung prosseguiu até 1930, quando parou de trabalhar no "Líber novus". Suas teses se baseavam em dois pontos fundamentais: (a) que a prática alquímica em laboratório estava relacionada a uma forma de prática de imaginação ativa e (b) que o conjunto dos símbolos e dos textos alquímicos revelados pelos alquimistas compartilhava do mesmo processo no qual ele havia se empenhado: o processo da individuação. (Shamdasani, 2010)

De acordo com Shamdasani (2010), Jung chegava a aconselhar seus pacientes:

Eu devia aconselhá-la a registrar tudo isso da maneira mais bela que você puder - em algum livro belamente encadernado. Vai parecer como se você estivesse banalizando visões - mas você precisa fazer isso - então você pode ficar livre delas. Se você fizer isso com esse olhar, por exemplo, elas deixarão de atrair você. Você nunca deve tentar fazer visões voltarem novamente. Pense nisso em sua imaginação e procure pintá-lo. Depois, quando estas coisas estiverem em algum livro precioso, você poderá ir ao livro e virar as páginas e para você será a sua igreja - sua catedral - os lugares silenciosos de seu espírito onde você encontrará renovação. Se alguém lhe disser que isso é mórbido ou neurótico e você lhe der ouvidos, você perderá sua alma - porque neste livro está sua alma. (p. 216)

Jung começou a elaborar o "Livro vermelho" visando a um mergulho, a um aprofundamento em si mesmo, tocando seu próprio material psíquico, suas próprias fantasias. Foi assim que ele se dispôs ao confronto com o inconsciente. Esses experimentos anímicos assemelharam-se de maneira espontânea aos processos da arte alquímica, sem que houvesse um intuito totalmente consciente do que estava sendo feito. A confecção de um códice parece ser organizadora para aquele que "sai da natureza" e se dirige a uma busca existencial. 


\section{Referências}

Arnheim, R. (2004). Intuição e intelecto na arte. São Paulo: Martins Fontes.

Bair, D. (2006). Jung, uma biografia (Vol. 2). São Paulo: Globo.

Boechat, W. (2014). O Livro Vermelho de Jung, jornada para profundidades desconhecidas. Petrópolis: Vozes.

Cassirer, E. (2005). O ensaio sobre o homem. São Paulo: Martins Fontes.

Didi-Huberman, G. (2009). Ser crânio. Belo Horizonte: Editora C/Arte.

Durand, G. (2002). As estruturas antropológicas do imaginário. São Paulo: Martins Fontes.

Jung, C. G. (1986). Símbolos da Transformação. In Obras Completas (Vol. V). Petrópolis: Ed. Vozes.

Jung, C. G. (1994). Psicologia e Alquimia. In Obras Completas (Vol. XII). Petrópolis: Ed. Vozes.

Jung, C. G. (2003). Estudos Alquímicos. In Obras Completas (Vol. XIII). Petrópolis: Ed. Vozes.

Neumann, E. (2006). A Grande Mãe. São Paulo: Cultrix.

Shamdasani, S. (2010). Liber Novus: o "Livro Vermelho" de C.G. Jung. In C. G. Jung, O Livro Vermelho, Liber Novus. Petrópolis: Ed. Vozes.

Minicurrículo: Mônika Oliveira - Psicoterapeuta de orientação junguiana; arteterapeuta. Mestre em Artes Visuais pela Universidade Federal do Rio de Janeiro.E-mail: monikaoc.artet@gmail.com 